\title{
Correction to: Designation of flyways and genetic structure of Woodpigeon Columba palumbus in Europe and Morocco
}

\section{Dalius Butkauskas ${ }^{1}$. Saulius Švažas ${ }^{1}$ - Antonio Bea ${ }^{2}$. Petras Prakas ${ }^{1}$ - Iñaki Olano ${ }^{2} \cdot$ Gennady Grishanov $^{3}$. Alexander Mischenko ${ }^{4}$. Alexander Kozulin ${ }^{5}$. Vitas Stanevičius ${ }^{1}$. András Báldi ${ }^{6}$. Frank Huysentruyt ${ }^{7}$. Daiva Vaitkuviené ${ }^{1} \cdot$ Yaroslav Red'kin $^{8}$}

Published online: 6 December 2019

(C) Springer-Verlag GmbH Germany, part of Springer Nature 2019

\section{Correction to: European Journal of Wildlife Research https://doi.org/10.1007/s10344-019-1336-9}

Figures 1-3 need to be replaced to cover the facts correctly.

In the old versions of Figures 1-3 (with indicated places of ringing and recovery) all available recoveries of Woodpigeons are provided.

In the corrected versions of Figures 1-3 only direct recoveries of Woodpigeons (with indicated periods of recoveries) are provided.

The online version of the original article can be found at https://doi.org/ 10.1007/s10344-019-1336-9

Dalius Butkauskas

dalius.butkauskas@gamtc.lt

Nature Research Centre, Akademijos 2, LT-08412 Vilnius, Lithuania

2 Ekos Estudios Ambientales, Donostia Etorbidea, Bajo 2, 20160 Lasarte, Spain

3 Baltic Federal I. Kant University, Universitetskaya 2, 236000 Kaliningrad, Russia

4 A. Severtsov Institute of Ecology and Evolution, Leninsky Prospect 33, Moscow 119071, Russia
5 Scientific Centre for Bioresources of Academy of Sciences, Akademicheskaya 27, BY-220072 Minsk, Belarus

6 Centre for Ecological Research, Hungarian Academy of Sciences, Alkotmány u. 2-4, Vácrátót 2163, Hungary

7 Research Institute for Nature and Forest, Gaverstraat 4, 9500 Geraardsbergen, Belgium

8 Zoological Museum of Moscow University, Bolshaya Nikitskaya Street 6, Moscow 125009, Russia 


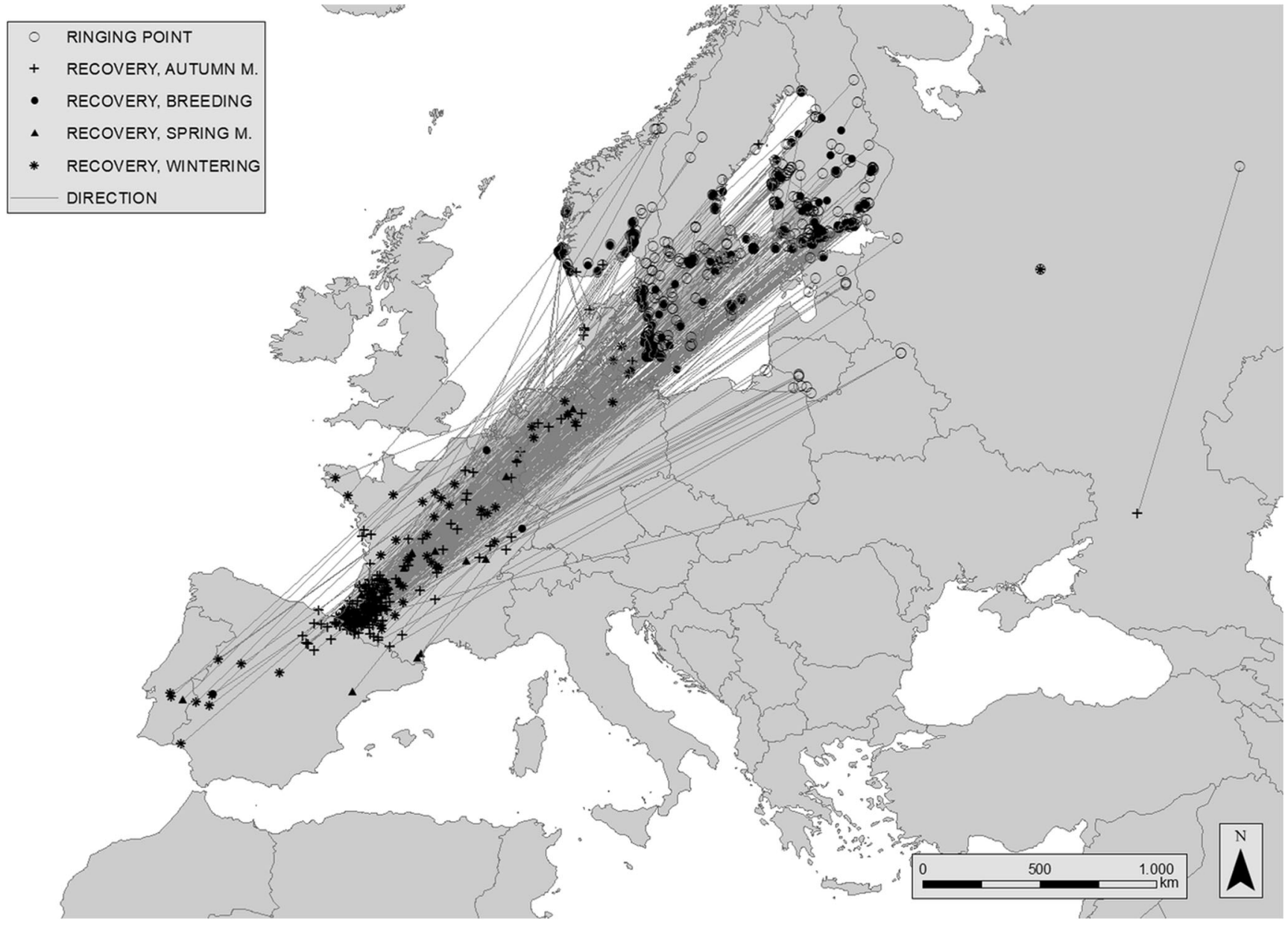




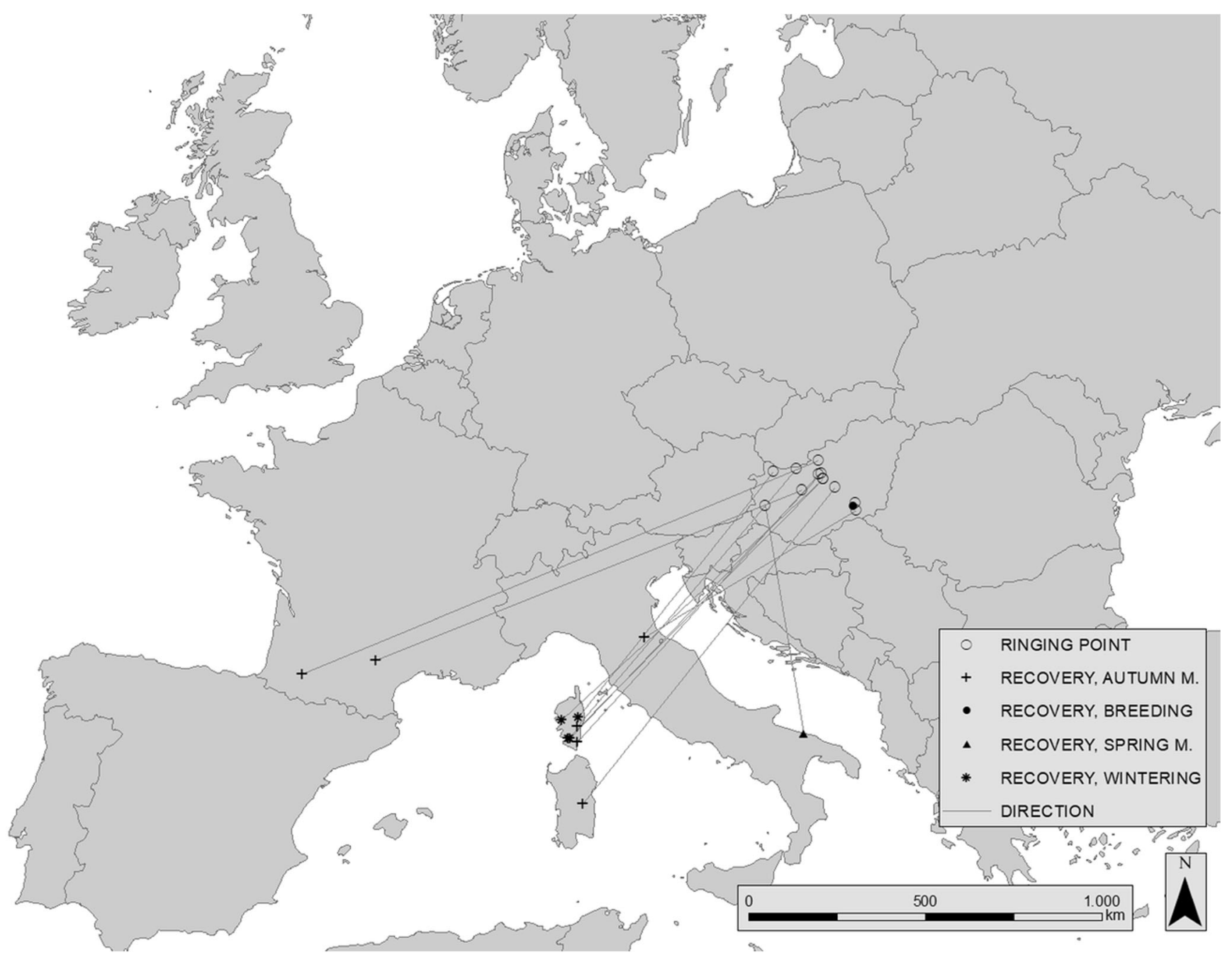




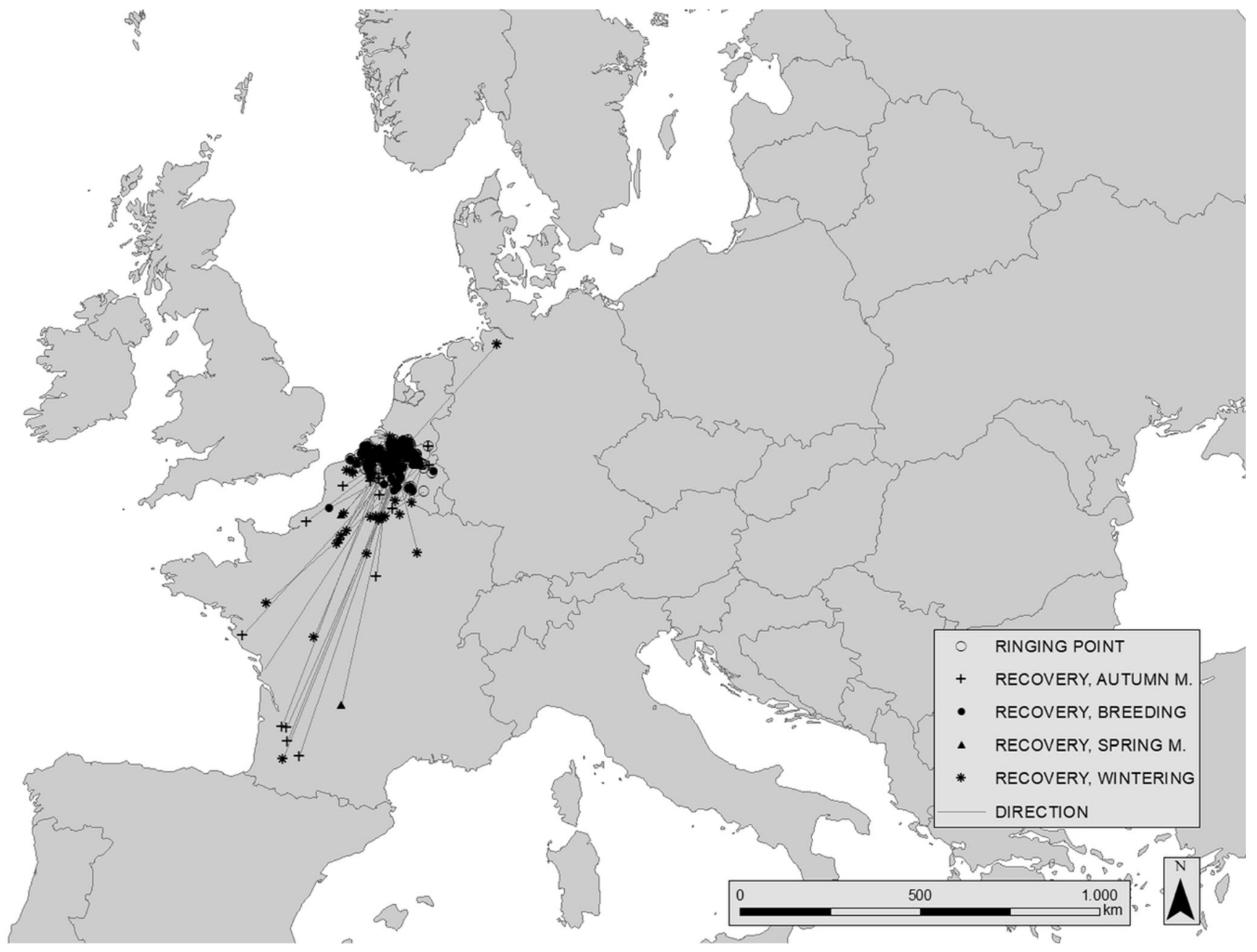

